\title{
Psychological Capital Mediating the Relationship Between Childhood Trauma and Alexithymia in Chinese Medical Students: A Cross-Sectional Study
}

This article was published in the following Dove Press journal: Psychology Research and Behavior Management

\author{
Chang-hong Zhang (D) \\ $\mathrm{Ge} \mathrm{Li}^{2}$ \\ Zhao-ya Fan' \\ Xiao-jun Tang' \\ Fan Zhang'
}

'School of Public Health and Management, Research Center for Medicine and Social Development, Collaborative Innovation Center of Social Risks Governance in Health, Chongqing Medical University, Chongqing 400016 , People's Republic of China; ${ }^{2}$ The Center of Experimental Teaching Management, Chongqing Medical University, Chongqing 40I33I, People's Republic of China
Correspondence: Fan Zhang

School of Public Health and Management, Research Center for Medicine and Social Development, Collaborative Innovation Center of Social Risks Governance in Health, Chongqing Medical University, Chongqing 4000 I6, People's Republic of China

Email epicqmu@163.com
Purpose: A much higher prevalence of alexithymia has been found in medical students compared with the general population. This study aimed to test the potential mediating effect of psychological capital on the relationship between childhood trauma and alexithymia in Chinese medical students, thereby providing clues for future interventions aimed at dealing with alexithymia in this population.

Methods: Convenience cluster sampling was used to recruit 1200 medical students in Chongqing, China. This cross-sectional study utilised the Childhood Trauma Questionnaire Short Form, the Toronto Alexithymia Scale, and the Psychological Capital Questionnaire. A structural equation model with maximum likelihood was used to study the mediating effect presented in the aim, and the significance of the mediating effect was examined by the bootstrap method. Multiple-group invariance analyses were also conducted to confirm the stability of the model.

Results: A total of 1018 were identified to have valid responses with a rate of $84.83 \%$. $38.4 \%$ were males, $61.6 \%$ were females. The prevalence of alexithymia was $16.5 \%$. Results of structural equation model showed that childhood trauma was positively related to alexithymia, with a standard path coefficient of 0.219 (C.R. $=6.644, \mathrm{P}<0.001$ ). The partial mediating effect of psychological capital was $0.060(\mathrm{P}<0.001)$, accounting for $21.51 \%$ of the total effect of childhood trauma on alexithymia. Results of bootstrap method showed that the lower and upper bounds of the $95 \%$ confidence interval did not contain 0 , and the multiple-group invariance analyses showed that the $p$ values of the changes in the degrees of freedom and chi-square value were greater than 0.05 , thus confirming the stability of the model.

Conclusion: Childhood trauma was a direct predictor of alexithymia among Chinese medical students, and the relationship between these two was partially mediated by psychological capital. Therefore, interventions aimed at enhancing psychological capital in this population may be effective at diminishing alexithymia.

Keywords: childhood trauma, alexithymia, psychological capital, medical students, mediating effect, interventions

\section{Introduction}

The outbreak of COVID-19 at the end of 2019 demonstrated that medical workers are indispensable. China, the most populous country in the world, experienced a lack of doctors leading to a gap between health service demand and healthcare supply. ${ }^{1}$ The doctor-patient ratio was 2.44 doctors for 1000 patients in 2017 in China, ${ }^{2}$ immensely lower than that in some developed countries. ${ }^{3}$ Over the past 
10 years, the attrition rate of medical graduates and physicians in China has been high. ${ }^{4}$ Therefore, Chinese medical students, a special group of students, have drawn continuous attention worldwide. However, compared with the general population, a much higher prevalence of alexithymia has been found in medical students. ${ }^{5}$ Doctors are required to be highly specialized; therefore, medical students need to spend more time and energy acquiring the necessary professional knowledge and skills; they are under more academic pressure than students in other majors. ${ }^{6,7}$ Confront an array of pressure mentioned above, medical students are at high risk of developing mental disorders such as burnout, ${ }^{8}$ depression, ${ }^{9}$ and anxiety. ${ }^{10}$ However, Alexithymia is a risk factor that increases vulnerability to these mental disorders, ${ }^{8,11,12}$ and may also be detrimental to poor doctor-patient communication in the future career of medical students. ${ }^{13}$ Thus, we should pay close attention to alexithymia in Chinese medical students.

Alexithymia was originally defined by Sifneos, who used it to describe the deficiencies in emotional skills of psychosomatic patients. ${ }^{14}$ A 5-year follow-up investigation in the general population showed that alexithymia was largely considered a stable personality trait. ${ }^{15}$ Alexithymia exists in healthy and unhealthy people, ${ }^{16}$ and it has been characterized by difficulties in identifying, analyzing, and expressing emotions; moreover, there some restrictions regarding imagination and externally oriented thinking. ${ }^{14}$ Alexithymia is correlated with emotional skillrelated problems, such as difficulties in building and maintaining interpersonal relationships, smaller social networks, reduced social skills. ${ }^{17}$

A cross-sectional study found that the prevalence of alexithymia in Chinese medical students was $15.7 \% .^{13}$ However, until now, studies on alexithymia have mainly been conducted in foreign medical students, such as Turkish and Romanian students, ${ }^{8,18}$ with only a few being conducted in Chinese medical students. Accordingly, there is a need for the collection of pertinent data on alexithymia in Chinese medical students if we are to better understand and provide clues for future interventions aimed at diminishing the negative outcomes of such personality traits.

Childhood trauma refers to psychological and physical harm suffered during childhood, including emotional, physical, and sexual abuse, as well as emotional and physical neglect. ${ }^{6,19,20}$ Childhood trauma has been confirmed as a significant risk factor for psychotic and mood disorders in later life. ${ }^{21,22}$ Additionally, some studies have suggested that childhood trauma is an important factor contributing to alexithymia; for example, a study in psychiatric patients found that childhood trauma, severe emotional neglect, and physical neglect were significantly related to higher levels of alexithymia. ${ }^{23}$ Another study in 5283 participants from the general population found that childhood neglect and abuse played a key role in the development of alexithymia, ${ }^{24}$ and Güle et al found that emotional abuse and neglect predicted the emergence of alexithymia in later life. ${ }^{25}$ However, little research has focused on the relationship between childhood trauma and alexithymia in Chinese medical students; we hypothesized that childhood trauma was related to alexithymia. Given that the number of Chinese medical students is high and that they may pose a great impact on the future health status of Chinese people, there is a clear need for more studies on this population.

If people suffer from childhood trauma, there is no way to remedy the fact that such trauma happened; however, we can still trace the pathways between childhood trauma and alexithymia, and this topic has caught the attention of the authors. We believe we may be able to reduce the impact of childhood trauma on alexithymia by intervening in the pathways that lead to alexithymia and reducing the prevalence of this personality trait. Lecours et al found that negative self-reported emotion was a mediator in the relationship between childhood emotional trauma and alexithymia during adulthood. ${ }^{26}$ However, the mechanisms that lead to alexithymia are complex and varied; therefore, more research is needed to build specific theoretical models for this personality trait.

Psychological capital, a term that represents the development of the positive psychological aspects of the human experience, includes four dimensions: self-efficacy, hope, optimism, and resilience. ${ }^{27}$ It has been shown that psychological capital can be exploited just like social resources, ${ }^{27}$ thus, we considered that it could be one of the mechanisms that may be protective for alexithymia. The reason for this thought can be found in the literature; Dong et al found that childhood trauma was associated with psychological resilience, ${ }^{28}$ while other studies showed that childhood trauma was related to depression ${ }^{29}$ and suicidal ideation $^{30}$ and that it might indirectly confer vulnerability to stressful life events. ${ }^{31}$ These results show that childhood trauma opposes three dimensions of psychological capital, namely, self-efficacy, hope, and optimism. Accordingly, we hypothesized that childhood trauma would have 


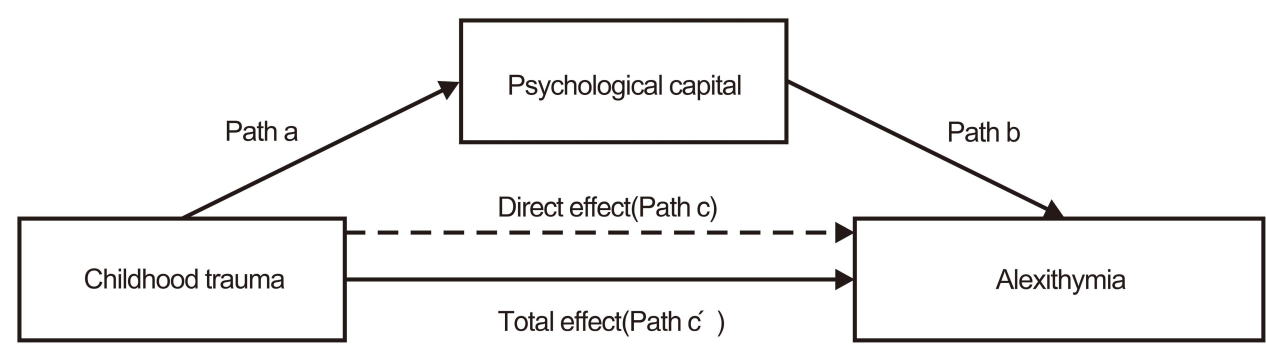

Figure I The hypothetical mediation model.

a negative effect on people's psychological capital. Meanwhile, a study showed that there is a correlation between psychological capital and alexithymia; Qin et al found that psychological capital could negatively predict alexithymia in nursing students, although the study remarked the need for more research exploring the relationship between these variables. ${ }^{32}$

Thus, this study aimed to analyze the relationship between alexithymia and childhood trauma, as well as the mediating effect of psychological capital in this relationship, in Chinese medical students. Summarizing, we hypothesized that childhood trauma could directly predict alexithymia and that their relationship could be mediated by psychological capital. The hypothetical theoretical model is shown in Figure 1. We hoped that this study would serve to enlighten future researchers on this theoretical relationship model and to provide clues to interventions aimed at dealing with alexithymia in Chinese medical students based on the development of psychological capital.

\section{Materials and Methods}

\section{Participants and Procedure}

In China, medical students are present both in medical universities and vocational schools; thus, to complement our data, we conducted a cross-sectional survey in the only one medical university and vocational school in Chongqing at the same time. We employed a convenience cluster sampling method to produce a sample. Participants were all medical students from both schools and were able to complete our questionnaire independently. We excluded those who were not willing to cooperate with the investigation. For this study, we utilized the following sample size calculation formula $n=\left(\mu a^{\wedge} 2 \pi\right.$ $(1-\pi)) / \delta^{\wedge} 2$, which allowed for a relative error of $15 \%$, so the absolute error $\delta=0.15 \pi$ and $95 \%$ confidence intervals were accepted; thus, $\mu \mathrm{a}=1.96$. According to previous research, the prevalence of alexithymia among Chinese medical students was $15.7 \%{ }^{13}$ So $\pi=15.7 \%$. Considering that $10 \%$ of the responses would be invalid, the minimum sample size in this study was $\mathrm{n}=[1.962 \times 15.7 \%(1-15.7 \%)] /$ $(0.15 \times 15.7 \%) 2 \approx 917$; however, we chose to expand the sample size to $n=917 \times(1+10 \%)=1009$.

We approached a total of 1200 medical students, 600 per university. After the researchers obtained informed consent from all participants, the latter completed a traditional paper-and-pencil questionnaire in a classroom with the guidance of well-trained researchers; average, it took about 30 minutes for participants to complete the anonymous questionnaire. Due to missing data, we excluded 182 individuals and left a final sample size of 1018 (valid response rate $=84.83 \%$ ).

\section{Ethical Statements}

This study was approved by the ethics committee of Chongqing Medical University (2018015) and in accordance with the Declaration of Helsinki. Participants were fully informed regarding the survey prior to participation. Completing and submitting the questionnaire was considered a proxy consent to participate. In this study, all participants were voluntary and the questionnaire was anonymous, we also used non-identifying codes, ensuring the confidentiality of the information.

\section{Instruments}

\section{Childhood Trauma Questionnaire-Short Form (CTQ-SF)}

The 28-item self-reported CTQ-SF is divided into the following five subscales, each including 5 items: emotional abuse, physical abuse, sexual abuse, emotional neglect, and physical neglect. ${ }^{33}$ It includes 25 clinical and 3 valid items. ${ }^{34}$ It is rated on a 5-point Likert-type scale, ranging from 1 (never) to 5 (very often). Total scores range from 25 to 125; these are calculated by summing up the scores in all items, thereby creating 
a composite score for each participant; higher scores indicate higher exposure to abuse/neglect experiences. ${ }^{34}$ The Chinese version of the Childhood Trauma questionnaireshort form has shown good reliability and validity among Chinese undergraduates and depressive samples, thereby indicating that the CTQ-SF is a good tool for assessing childhood trauma. ${ }^{35}$ Thus, we utilized this version, in the current study, the cronbach's alpha was 0.835 .

\section{Toronto Alexithymia Scale (TAS-20)}

The 20-item self-reported TAS-20 is divided into the three following subscales: difficulty in identifying feelings ( 7 items), difficulty in describing feelings (5 items), and externally oriented thinking ( 8 items). ${ }^{36,37}$ It is rate $\mathrm{d}$ on a 5-point scale, ranging from 1 (strongly disagree) to 5 (strongly agree), and total scores range from 20 to 100 ; these are calculated by summing up the scores in all items, thereby creating a composite score for each participant. Higher scores indicate higher levels of alexithymia. In traditional cutoffs of the TAS- 20 scale, a total score $>60$ indicated that the participant had alexithymia; ${ }^{38}$ additionally, many studies have suggested that the TAS-20 is applicable to Chinese people. ${ }^{13}$ Thus, we applied its Chinese version in this study, and the Cronbach's alpha was 0.832 .

\section{Psychological Capital Questionnaire (PCQ)}

The 24-item PCQ was originally developed by Luthans et $\mathrm{al}^{27}$ and subsequentially translated to and revised in Chinese by Wen et al; ${ }^{39}$ It has the following four subscales: hope (6 items), resilience (6 items), optimism (6 items), and self-efficacy (6 items). Each item is rated on a 6-point scale, ranging from 1 (strongly disagree) to 6 (strongly agree), and total scores range from 24 to 144; these are calculated by summing up the scores in all items, thereby creating a composite score for each participant. Higher scores indicate higher levels of psychological capital, with a total score of 100 or more indicating a good level of psychological capital. In this study, Cronbach's alpha was 0.928.

\section{Data Analysis}

We used descriptive analysis to describe participants' demographic characteristics, and enumeration data were described as percentages, while normally distributed continuous data were described as mean \pm standard deviation. We used a $t$-test to analyze differences in alexithymia between variables. Additionally, we used the Pearson correlation coefficient to evaluate the associations between variables and a structural equation model (SEM) with maximum likelihood to evaluate the mediating effect of psychological capital on the relationship between childhood trauma and alexithymia. We used participants' scores for the subscales of all instruments (ie, CTQ-SF, PCQ, and TAS-20) as measurement variables, and their total scores as latent variables. The detailed structural equation model is shown in Figure 2.

Based on prior research, ${ }^{40}$ the model fit was estimated by the root mean square error of approximation (RMSEA), comparative fit index (CFI), Tucker Lewis index (TLI), incremental fit index (IFI), normed fit index (NFI), and Chi-square

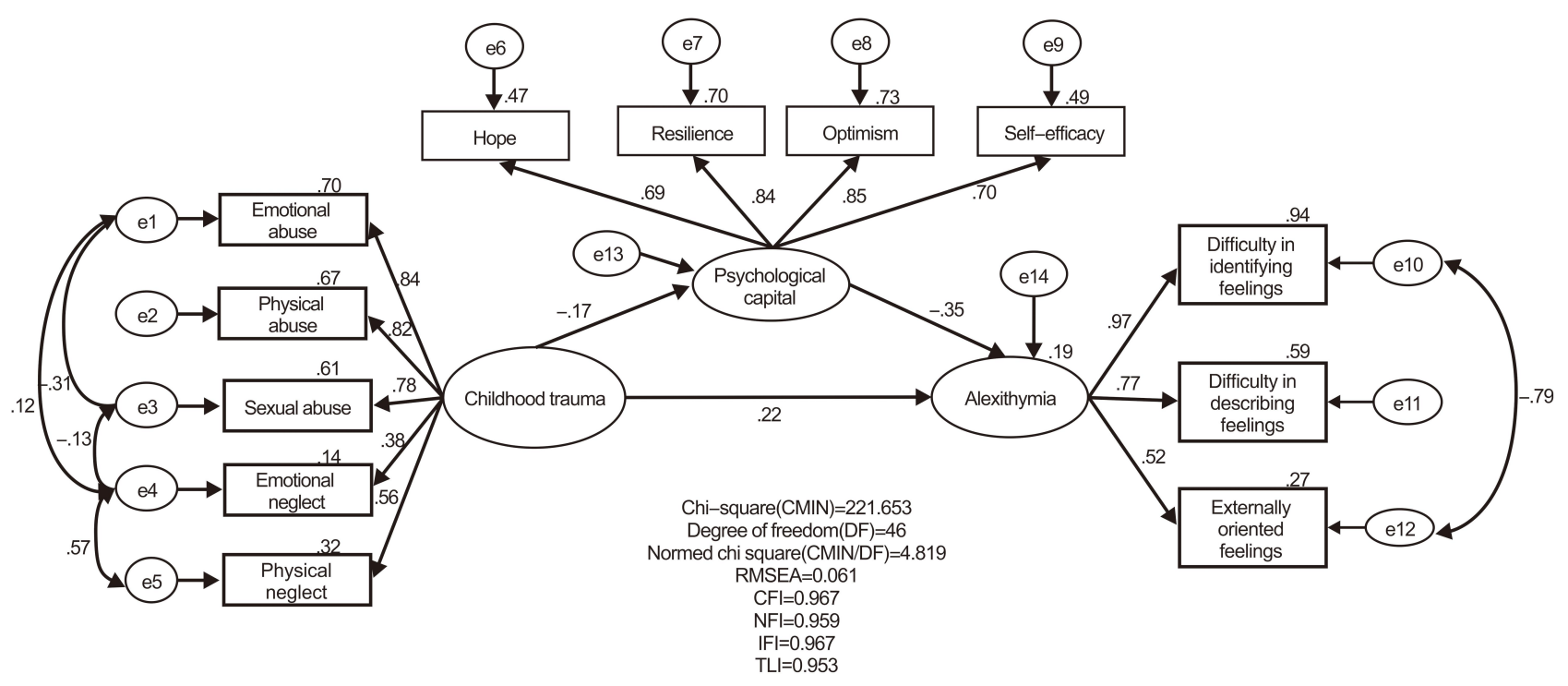

Figure 2 The structural equation modelling for the hypothetical model.

Abbreviations: RMSEA, root mean square error; CFI, comparative fit index; NFI, normed fit index; IFI, incremental fit index; TLI, Tucker Lewis index. 
statistic $(\chi 2) /$ degrees of freedom (df) (CMIN/DF). According to the literature, ${ }^{41}$ we deemed that a model with RMSEAs below 0.08 , CFI, TLI, IFI, and NFI values above 0.90 , and CMIN/DF values below 5, was a model with appropriate goodness of fit. We used standardized estimates for all paths and the bootstrap method to examine the significance of the mediating effect of psychological capital; we bootstrapped 5000 samples from the data and calculated $95 \%$ bootstrap confidence intervals (CI). Based on a prior study, ${ }^{42}$ if the $95 \%$ $\mathrm{CI}$ did not contain a 0 , the mediating effect was significant.

In our study, there were between-participant differences in the scores for the TAS-20 regarding those from the countryside, city, vocational schools, and university students. Therefore, we conducted multiple-group invariance analysis to test the invariance of this model and confirm that its stability crossed those variables. First, all structural paths could vary freely; then, we added equality constraints on each path, subsequentially assessing the fit of the unconstrained and constrained models. We used chi-square tests to estimate significant differences between the unconstrained- and constrained-equal models; we applied measurement (ie, latent construct factor loadings) and structural weights (ie, regression coefficients) according to the changes in degrees of freedom $(\Delta \mathrm{df})$ and chi-square value $\left(\Delta \chi^{2}\right)$ compared to the unconstrained model. ${ }^{43}$ The chi-square value of $p>0.05$ indicated that there were no differences between the models and that the applicability and stability of the model was confirmed across groups. We utilized SPSS 20.0 Statistical software and Amos 23.0 for statistical analysis, and statistical significance was set at $\mathrm{p}<0.05$.

\section{Results}

\section{Demographic Information and Differences in Alexithymia Among Variables}

The average age of participants was $19.53 \pm 1.20$ years. The demographics of the participants are as follows: males (38.4\%) and females (61.6\%); students from countryside (46\%) and city (54\%); only child (38.5\%) and non-only child (61.5\%); students in vocational school (47.7\%) and university (52.3\%). Participants' mean total score for the TAS-20 was $52.38 \pm 9.25 ; 16.5 \%$ of all participants showed a score higher than 60 , indicating that they had alexithymia. There were significant differences in participants' total scores for the TAS-20 by residence $(t=3.000$; $\mathrm{p}<0.01)$ and school types $(\mathrm{t}=3.456 ; \mathrm{p}<0.01)$. Detailed results are shown in Table 1.

\section{Correlations Between Childhood Trauma, Psychological Capital, and Alexithymia}

A preliminary analysis of the correlations between these variables indicated a moderate positive correlation between childhood trauma and alexithymia ( $\mathrm{r}=0.314$, $\mathrm{p}<0.01$ ), and a moderate negative correlation between childhood trauma and psychological capital $(\mathrm{r}=-0.229$, $\mathrm{p}<0.01$ ), and between psychological capital and alexithymia $(r=-0.370, p<0.01)$. Detailed results are shown in Table 2.

\section{Psychological Capital Mediates the Relationship Between Childhood Trauma and Alexithymia}

\section{Results of Structural Equation Model}

As shown in Figure 2 and Table 3, Chi-square $(\mathrm{CMIN})=$ 221.653 , degree of freedom $(\mathrm{DF})=46, \mathrm{CMIN} / \mathrm{DF}=4.819$, RMSEA $=0.061, \quad$ CFI $=0.967, \quad \mathrm{NFI}=0.959, \quad \mathrm{IFI}=0.967$, $\mathrm{TLI}=0.953$; the fit indices for the hypothetical model showed good model fit. In this model, the three latent variables were significantly inter-correlated. The standardized path coefficients of Paths a (ie, from Childhood Trauma-Psychological Capital), b (ie, from Psychological Capital-Alexithymia), and c (ie, from Childhood Trauma-Alexithymia) were $-0.172,-0.346$, and 219, respectively. Using Path c as an example, for each SD decrease in childhood trauma, there was an SD increase in alexithymia of 0.219 ; additionally, the partial mediating effect of psychological capital was significant $(\mathrm{p}<0.001)$ with a path coefficient of 0.06 , constituting $21.51 \%$ (ie, direct effect/total effect) of the total effect.

\section{Multiple-Group Invariance Analysis}

As shown in Table 4, the measurement and structural weights for the constrained models were compared to those in the unconstrained model. The $p$ values of the changes in the degrees of freedom and chi-square values were greater than 0.05 , confirming the stability of the model.

\section{Discussion}

In this study, the prevalence of alexithymia in Chinese medical students was $16.5 \%$; thereby, our findings concur with prior research. ${ }^{13}$ This indicates that approximately a sixth of our sample of Chinese medical students had alexithymia, a personal trait that, as discussed in the Introduction, may be detrimental to Chinese medical students. 
Table I Descriptive Statistics and Differences in Alexithymia Among Variables $(n=1018)$

\begin{tabular}{|c|c|c|c|c|c|}
\hline Variables & n (\%) & $\begin{array}{l}\text { Difficulty in Identifying } \\
\text { Feelings } \\
\text { Mean (SD) }\end{array}$ & $\begin{array}{l}\text { Difficulty in Describing } \\
\text { Feelings } \\
\text { Mean (SD) }\end{array}$ & $\begin{array}{l}\text { Externally Oriented } \\
\text { Thinking } \\
\text { Mean (SD) }\end{array}$ & $\begin{array}{l}\text { Alexithymia } \\
\text { Mean (SD) }\end{array}$ \\
\hline \multicolumn{6}{|l|}{ Gender } \\
\hline Male & $391(38.4)$ & $\mid 7.81(5.22)$ & $13.51(3.24)$ & $20.96(3.56)$ & $52.28(9.87)$ \\
\hline Female & $627(6 I .6)$ & I7.83(4.63) & $|3.5|(2.88)$ & $21.11(3.33)$ & $52.45(8.85)$ \\
\hline & & -0.088 & -0.017 & -0.660 & -0.286 \\
\hline P-value & & 0.930 & 0.987 & 0.510 & 0.775 \\
\hline \multicolumn{6}{|l|}{ Residence } \\
\hline Countryside & $468(46.0)$ & $18.09(4.73)$ & $13.80(2.86)$ & $21.43(3.04)$ & $53.32(8.55)$ \\
\hline City & $550(54.0)$ & $17.60(4.97)$ & $13.26(3.13)$ & $20.73(3.68)$ & $51.58(9.74)$ \\
\hline $\mathrm{t}$ & & 1.589 & 2.880 & 3.364 & 3.000 \\
\hline P-value & & 0.112 & $0.004 * *$ & $0.001 * *$ & $0.003 * *$ \\
\hline \multicolumn{6}{|l|}{ Only child } \\
\hline Yes & $392(38.5)$ & $|7.6|(5.04)$ & $13.26(3.25)$ & $20.79(3.66)$ & $51.66(10.01)$ \\
\hline No & $626(61.5)$ & I7.96(4.75) & $13.66(2.86)$ & $21.22(3.25)$ & $52.83(8.72)$ \\
\hline $\mathrm{t}$ & & -1.095 & -2.006 & -1.911 & -1.915 \\
\hline P-value & & 0.274 & $0.045^{*}$ & 0.056 & 0.056 \\
\hline \multicolumn{6}{|l|}{ School types } \\
\hline Vocational school & $486(47.7)$ & I8.27(5.07) & $13.72(2.95)$ & $21.44(3.25)$ & $53.42(9.14)$ \\
\hline University & $532(52.3)$ & $|7.4|(4.63)$ & $13.32(3.07)$ & $20.70(3.53)$ & $51.43(9.26)$ \\
\hline $\mathrm{t}$ & & 2.822 & 2.116 & 3.457 & 3.456 \\
\hline$P$-value & & $0.005^{* *}$ & $0.035^{*}$ & $0.001 * *$ & $0.00 I^{* *}$ \\
\hline
\end{tabular}

Notes: $* \mathrm{P}<0.05,{ }^{* *} \mathrm{P}<0.01$; " $\mathrm{t}$ " refers to the statistical value of the student's $t$ test.

Our results also confirmed the hypothetical theoretical model we proposed, namely, that childhood trauma and psychological capital can directly predict alexithymia, respectively, and that the relationship between childhood trauma and alexithymia was partially mediated by psychological capital, which constitutes $21.51 \%$. This result means that if we enhance psychological capital, the effects of childhood trauma on alexithymia and the levels of alexithymia can be reduced. Hereinafter, we discuss each of the paths and the full model.

We found that childhood trauma could directly predict alexithymia; this result finds consonance in the literature. A study in the general population found that emotional neglect during childhood was the strongest predictor for alexithymia. ${ }^{44}$ Chen et al also found that alexithymia among adult prisoners could be explained by their experience of childhood traumas, including both emotional abuse and physical neglect. ${ }^{45}$ Moreover, alexithymia may owe to previous traumatic experiences and feelings of shame, which could be conceptualized as maladaptive-reactive constructs. ${ }^{46}$

The scientific literature shows that childhood is a crucial period for both physical and mental development; accordingly, childhood experiences of abuse and neglect have been confirmed as risk factors for a variety of psychological disturbances and personality disorders, ${ }^{21,22,47}$ all of these disorders can affect the emotional, cognitive, behavioral, and physical development in later life, ${ }^{48}$ making those with childhood maltreatment experiences more vulnerable to alexithymia. Thus, childhood maltreatment can contribute to an impaired emotional development and disrupt the biological and psychological processes of affect regulation - $^{49}$ which may result in alexithymia. ${ }^{23,50}$ Moreover, children who are in severely abusive environments often do not learn to rely on others, even when they need help to regulate their emotional experience or effectively self-soothe their psychological state, ${ }^{50}$ another study showed that childhood trauma experiences can affect people's ability to communicate and identify emotions. ${ }^{47}$ Moreover, Paivio et al confirmed that childhood emotional maltreatment might have a negative impact on children's understanding of emotions, making their ability to recognize and distinguish emotions poorly, thereby leading to alexithymia. ${ }^{51}$ Summarizing, the literature and our results corroborate that childhood trauma could directly predict alexithymia. 
Table 2 Descriptive Statistics and Correlations Among Variables in the Whole Sample $(r, n=1018)$

\begin{tabular}{|c|c|c|c|c|}
\hline Variables & MISD & Childhood Trauma & Psychological Capital & Alexithymia \\
\hline Childhood trauma & $37.24 \pm 11.80$ & 1 & $-0.229 * *$ & $0.314 * *$ \\
\hline Emotional abuse & $7.33 \pm 2.81$ & $0.765 * *$ & $-0.199 * *$ & $0.248 * *$ \\
\hline Emotional neglect & $10.25 \pm 4.88$ & $0.775 * *$ & $-0.246 * *$ & $0.291 * *$ \\
\hline Physical abuse & $6.14 \pm 2.55$ & $0.744 * *$ & $-0.075^{*}$ & $0.173 * *$ \\
\hline Physical neglect & $7.80 \pm 3.06$ & $0.822 * *$ & $-0.186 * *$ & $0.253 * *$ \\
\hline Sexual abuse & $5.72 \pm 2.21$ & $0.655^{* *}$ & $-0.08 I^{* *}$ & $0.166 * *$ \\
\hline Psychological capital & $100.51 \pm 15.66$ & $-0.229 * *$ & 1 & $-0.370 * *$ \\
\hline Hope & $24.82 \pm 4.7 \mid$ & $-0.181 * *$ & $0.867^{* *}$ & $-0.317 * *$ \\
\hline Resilience & $25.00 \pm 4.59$ & $-0.181 * *$ & $0.87 I^{* *}$ & $0.320 * *$ \\
\hline Optimism & $25.15 \pm 5.02$ & $-0.245^{* *}$ & $0.805^{* *}$ & $-0.295^{* *}$ \\
\hline Self-efficacy & $25.55 \pm 4.51$ & $-0.150 * *$ & $0.784 * *$ & $-0.300 * *$ \\
\hline Alexithymia & $52.38 \pm 9.25$ & $0.314 * *$ & $-0.370 * *$ & 1 \\
\hline Difficulty in identifying feelings & $17.82 \pm 4.86$ & $0.304 * *$ & $-0.336 * *$ & $0.896 * *$ \\
\hline Difficulty in describing feelings & $|3.5| \pm 3.02$ & $0.240 * *$ & $-0.304^{* *}$ & $0.860 * *$ \\
\hline Externally oriented thinking & $21.05 \pm 3.42$ & $0.204^{* *}$ & $-0.256 * *$ & $0.672 * *$ \\
\hline
\end{tabular}

Notes: $M \pm S D$ refers to mean value standard deviation; ${ }^{*} p<0.05$, ** $p<0.01$.

Table 3 The Standard Effects in the Hypothetical Model

\begin{tabular}{|l|l|l|l|l|l|}
\hline \multirow{2}{*}{ Effect } & Path & Estimate & P-value & \multicolumn{2}{|l|}{ 95\% Confidence Intervals } \\
\cline { 4 - 6 } & & & & Lower Bounds & Upper Bounds \\
\hline \multirow{2}{*}{ Direct } & $\mathrm{CT} \rightarrow$ Alexithymia & 0.219 & $<0.001$ & 0.129 & 0.284 \\
& $\mathrm{CT} \rightarrow \mathrm{PC}$ & -0.172 & $<0.001$ & -0.264 & -0.080 \\
& $\mathrm{PC} \rightarrow$ Alexithymia & -0.346 & $<0.001$ & -0.430 & -0.287 \\
\hline Indirect & $\mathrm{CT} \rightarrow \mathrm{PC} \rightarrow$ Alexithymia & 0.060 & $<0.001$ & 0.071 & 0.261 \\
\hline Total effect & $\mathrm{CT} \rightarrow$ Alexithymia & 0.279 & $<0.001$ & 0.190 & 0.347 \\
\hline
\end{tabular}

Abbreviations: $\mathrm{CT}$, childhood trauma; PC, psychological capital.

Table 4 The Results of Multiple-Group Invariance Analysis

\begin{tabular}{|l|l|l|l|l|l|l|l|l|l|l|l|}
\hline Variables & Model & $\chi^{2}$ & df & CFI & NFI & TLI & RMSEA & IFI & $\Delta \chi^{2}$ & $\Delta$ df & P-value \\
\hline Residence & UN & 265.988 & 92 & 0.967 & $0.95 I$ & 0.953 & 0.043 & 0.967 & - & - \\
& MW & 275.418 & 100 & 0.967 & 0.949 & 0.956 & 0.042 & 0.967 & 9.431 & 8 & 0.307 \\
& SW & $28 I .446$ & 103 & 0.966 & 0.948 & 0.957 & 0.041 & 0.967 & 15.456 & 11 & 0.162 \\
\hline School & UN & 294.234 & 92 & 0.960 & 0.946 & 0.945 & 0.047 & 0.962 & - & - & \\
\hline type & MW & 307.909 & 99 & 0.961 & 0.944 & 0.948 & 0.046 & 0.961 & 13.674 & 7 & 0.057 \\
& SW & 309.184 & 102 & 0.961 & 0.943 & 0.950 & 0.045 & 0.961 & 14.949 & 10 & 0.134 \\
\hline
\end{tabular}

Abbreviations: UN, unconstrained; MW, measurement weights; SW, structural weights; $\chi^{2}$, chi-square statistic; df, degrees of freedom; CFI, comparative fit index; NFI, normed fit index; TLI, Tucker Lewis index; RMSEA, root mean square error; IFI, incremental fit index; $\Delta \chi^{2}$ and $\Delta$ df refer to the difference in Chi-square statistic and degrees of freedom respectively.

Our results highlighted that psychological capital partially mediated the relationship between childhood trauma and alexithymia. This result is like that of a previous study, ${ }^{32}$ but few research have focused on this specific relationship between these three variables; still, our finding may be explained by the following literature. Studies have found that the developing brain is sensitive to and can be permanently altered by childhood maltreatment experiences, ${ }^{52}$ making those who experience childhood trauma more vulnerable to mental illness. ${ }^{53}$ Moreover, 
poor mental health has been shown to negatively correlate with psychological capital. ${ }^{54}$ An interdisciplinary literature review showed a strong connection between childhood trauma and psychological difficulties in later life (eg, depression, suicide, and addiction). ${ }^{52}$ Thus, childhood trauma evokes negative outcomes for psychological capital.

As aforementioned, psychological capital comprises four positive psychological resources, namely, self-efficacy, hope, optimism, and resilience, ${ }^{27}$ and studies have confirmed that a history of childhood maltreatment experiences relates to lower optimism, ${ }^{55}$ resilience, ${ }^{28}$ and self-efficacy. ${ }^{56}$ Accordingly, our results underpinned that childhood trauma was negatively correlated with psychological capital. Subsequently, the changes in people's psychological capital can also have an impact on alexithymia. Confirming this assumption, a study showed that high psychological capital -as an essential psychological resource for the positive development of individuals - has the potential to overcome obstacles in life. ${ }^{57}$ This is because it can mitigate the effects of negative events on people; for example, a study found that psychological capital could negate the negative influence of unemployment on wellbeing, thus facilitating reemployment. ${ }^{58}$ As shown, alexithymia is a consequence of previous childhood traumatic experiences; ${ }^{46}$ additionally, it has been confirmed that efficacy, a subdimension of psychological capital, can moderate the bullying/post-traumatic stress disorder relationship in a study among experienced nurses. ${ }^{59}$ A study has also implied that people high in psychological capital deal better with trauma, especially through resilience, showing that this specific trait is pivotal in overcoming post-trauma stress disorder. ${ }^{57}$ What is more important is that psychological capital can motivate individuals to seek for favorable resources. Individuals with a high level of psychological capital are better able to identify their own emotions and properly express their emotions, thus reducing alexithymia. This result supports the resource conservation theory proposed by Hobfoll (COR). ${ }^{60}$ Thus, our results and the literature highlight that psychological capital is negatively correlated with alexithymia and can mediate the influence of childhood trauma on alexithymia among Chinese medical students.

\section{Limitations}

Nevertheless, the present study has some limitations that should be acknowledged. First, this was a cross-sectional study, so any causal relationship derived from our results should be made cautiously; further studies are warranted to increase the reliability of our findings, such as cohort and randomized controlled trial studies. Accordingly, the authors intend to conduct further research based on the current findings.

Second, participants in this study were all recruited in Chongqing; thus, our sample for this study does not represent all medical students in China, even if according to, ${ }^{61}$ Chongqing has been remarked as a "miniature of China." Consequentially, our findings may reflect some localized problems existent only in Chongqing, denoting that further studies are warranted to confirm if our inferences can be applied nationally — and potentially internationally.

Third, our sampling method (ie, convenience cluster sampling) might have evoked selection bias; still, we remark that we had a large sample that covered almost all majors. Further studies with random sampling are warranted.

\section{Conclusion}

The hypothetical mediation model we proposed was stable. Childhood trauma was a direct predictor of alexithymia in Chinese medical students, and their relationship was partially mediated by psychological capital. Therefore, interventions aimed at enhancing psychological capital in Chinese medical students may serve to help diminish alexithymia in this population.

\section{Acknowledgments}

We are very thankful to all the authors for their support and to the school superintendent for assisting us with the investigation. We also would like to thank Editage (www. editage.cn) for English language editing.

\section{Author Contributions}

All authors made substantial contributions to conception and design, acquisition of data, or analysis and interpretation of data; took part in drafting the article or revising it critically for important intellectual content; agreed to submit to the current journal; gave final approval of the version to be published; and agree to be accountable for all aspects of the work.

\section{Funding}

Funding was provided by Chongqing Science and Technology Commission, grant number cstc2017jcyjAX 0004.

\section{Disclosure}

The authors report no conflicts of interest in this work. 


\section{References}

1. Zhang S, Wang J, Xie F, et al. A cross-sectional study of job burnout, psychological attachment, and the career calling of Chinese doctors. BMC Health Serv Res. 2020;20(1):193. doi:10.1186/s12913-0204996-y

2. China: China Statistical Yearbook. Available from: http://www.stats. gov.cn/tjsj/ndsj/2017/indexeh.htm. Accessed. 2017.

3. Wan Q, Zhou W, Li Z, et al. Work engagement and its predictors in registered nurses: a cross-sectional design. Nurs Health Sci. 2018;20 (6):1-7. doi:10.1111/nhs.12424

4. Lien SS, Kosik RO, Fan AP, et al. 10-year trends in the production and attrition of Chinese medical graduates: an analysis of nationwide data. Lancet. 2016;388:S11. doi:10.1016/S0140-6736(16)31938-9

5. Lală A, Bobîrnac G, Tipa R. Stress levels, Alexithymia, Type A and Type C personality patterns in undergraduate students. $J$ Med Life. 2010;3(2):200-205.

6. Bond AR, Mason HF, Lemaster CM, et al. Embodied health: the effects of a mind-body course for medical students. Med Educ Online. 2013;18:1-8. doi:10.3402/meo.v18i0.20699

7. Wen Z, Ruiqi, et al. Prevalence of mental health problems among medical students in China: a meta-analysis. Medicine. 2019;98(18): e15337. doi:10.1097/MD.0000000000015337

8. Popavelea O, Diaconescu L, Mihăilescu A, et al. Burnout and its relationships with alexithymia, stress, and social support among Romanian medical students: a cross-sectional study. Int $J$ Environ Res Public Health. 2017;14(6):560. doi:10.3390/ijerph14060560

9. Bassols AM, Okabayashi LS, Da SAB, et al. First- and last-year medical students: is there a difference in the prevalence and intensity of anxiety and depressive symptoms?. Revista Brasileira de Psiquiatria. 2014;36(3):233-240. doi:10.1590/1516-4446-2013-1183

10. Mao Y, Zhang N, Liu J, et al. A systematic review of depression and anxiety in medical students in China. BMC Med Educ. 2019;19 (1):327. doi:10.1186/s12909-019-1744-2

11. Taycan O, Taycan SE, Cihat. Relationship of burnout with personality, alexithymia, and coping behaviors among physicians in a semiurban and rural area in Turkey. Arch Environ Occup Health. 2014;69(3):159-166. doi:10.1080/19338244.2013.763758

12. Yuan Y, Zhang Y, Zhao Y, et al. Investigation of health anxiety and its related factors in nursing students. Neuropsychiatr Dis Treat. 2014;10:1223. doi:10.2147/NDT.S61568

13. Zhu Y, Luo T, Liu J, et al. Influencing factors of alexithymia in Chinese medical students: a cross-sectional study. BMC Med Educ. 2017;17(1):66. doi:10.1186/s12909-017-0901-8

14. Sifneos PE. The prevalence of 'alexithymic' characteristics in psychosomatic patients. Psychother Psychosom. 1973;22(2):255-262. doi:10.1159/000286529

15. Salminen JK, Saarijarvi S, Toikka T, et al. Alexithymia behaves as a personality trait over a 5-year period in Finnish general population. J Psychosomat Res. 2006;61(2):275-278. doi:10.1016/j.jpsychores. 2006.01.014

16. Lane RD, Sechrest L, Riedel R. Sociodemographic correlates of alexithymia. Compr Psychiatry. 1998;39(6):377-385. doi:10.1016/ s0010-440x(98)90051-7

17. Timoney LR, Holder MD. Correlates of Alexithymia. In: Timoney LR, Holder MD, eds. Emotional Processing Deficits and Happiness. Dordrecht: Springer; 2013:41-60. doi: 10.1007/978-94007-7177-218.

18. Balaban H, Semiz M, Senturk IA, et al. Migraine prevalence, alexithymia, and post-traumatic stress disorder among medical students in Turkey. J Headache Pain. 2012;13(6):459-467. doi:10.1007/s10194012-0452-7

19. Morgan C, Fisher H. Environment and schizophrenia: environmental factors in schizophrenia: childhood trauma - a critical review. Schizophr Bull. 2007;33(1):3-10. doi:10.1093/schbul/sbl053
20. Zhang S, Lin X, Yang T, et al. Prevalence of childhood trauma among adults with affective disorder using the Childhood Trauma Questionnaire: a meta-analysis. J Affect Disord. 2020;276:546-554. doi:10.1016/j.jad.2020.07.001

21. Quide Y, Girshkin L, Watkeys OJ, et al. The relationship between cortisol reactivity and emotional brain function is differently moderated by childhood trauma, in bipolar disorder, schizophrenia and healthy individuals. Eur Arch Psychiatry Clin Neurosci. 2020. doi:10.1007/s00406-020-01190-3

22. Nogovitsyn N, Addington J, Souza R, et al. Childhood trauma and amygdala nuclei volumes in youth at risk for mental illness. Psychol Med. 2020:1-8. doi:10.1017/s0033291720003177.

23. Zlotnick C, Mattia JI, Zimmerman M. The relationship between posttraumatic stress disorder, childhood trauma and alexithymia in an outpatient sample. J Trauma Stress. 2001;14(1):177-188. doi:10. 1023/A:1007899918410

24. Terock J, Van der Auwera S, Janowitz D, et al. Childhood trauma and functional variants of 5-HTTLPR are independently associated with alexithymia in 5283 subjects from the general population. Psychother Psychosom. 2018;87(1):58-61. doi:10.1159/000484143

25. Gulec MY, Altintas M, Inanc L, et al. Effects of childhood trauma on somatization in major depressive disorder: the role of alexithymia. J Affect Disord. 2013;146(1):137-141. doi:10.1016/j. jad.2012.06.033

26. Lecours S, Philippe FL, Boucher M-E, et al. Negative self-evaluating emotions as mediator in the relationship between childhood emotional trauma and alexithymia in adulthood. $J$ Am Psychoanal Assoc. 2016;64(5):1027-1033. doi:10.1177/0003065116675876

27. Luthans F, Avey JB, Avolio BJ, et al. Psychological capital development: toward a micro-intervention. J Organ Behav. 2006;27: 387-393. doi:10.1002/job.373

28. Dong C, Xu R, Xu L. Relationship of childhood trauma, psychological resilience, and family resilience among undergraduate nursing students: a cross-sectional study. Perspect Psychiatr Care. 2020. doi:10.1111/ppc. 12626

29. De Venter M, Elzinga BM, Van den Eede F, et al. The associations between childhood trauma and work functioning in adult workers with and without depressive and anxiety disorders. Eur Psychiatry. 2020;63(1):1-28. doi:10.1192/j. eurpsy.2020.70

30. Kwon A, Min D, Kim Y, et al. Interaction between catechol-O-methyltransferase polymorphism and childhood trauma in suicidal ideation of patients with post-traumatic stress disorder. Brain Behav. 2020;10(8):e01733. doi:10.1002/brb3.1733

31. Weissman DG, Lambert HK, Rodman AM, et al. Reduced hippocampal and amygdala volume as a mechanism underlying stress sensitization to depression following childhood trauma. Depress Anxiety. 2020;37(9):916-925. doi:10.1002/da.23062

32. Qin Y, Yuli LI, Liu J, et al. Mediating effect of psychological capital between childhood trauma and alexithymia in nursing students. Chinese Ment Health J. 2018;32(6):90-96.

33. Thombs BD, Bernstein DP, Lobbestael J, et al. A validation study of the Dutch Childhood Trauma Questionnaire-Short Form: factor structure, reliability, and known-groups validity. Child Abuse Negl. 2009;33(8):518-523. doi:10.1016/j.chiabu.2009.03.001

34. a DPB, b JAS, c MDN, et al. Development and validation of a brief screening version of the Childhood Trauma Questionnaire. Child Abuse Negl. 2003;27(2):169-190. doi:10.1016/S0145-2134(02)005 41-0

35. He J, Zhong X, Gao Y, et al. Psychometric properties of the Chinese version of the Childhood Trauma Questionnaire-Short Form (CTQ-SF) among undergraduates and depressive patients. Child Abuse Negl. 2019;91:102-108. doi:10.1016/j.chiabu.2019.03.009

36. Bagby RM, Parker JD, Taylor GJ. The twenty-item Toronto Alexithymia Scale-I. Item selection and cross-validation of the factor structure. J Psychosomat Res. 1994;38(1):23-32. doi:10.1016/00223999(94)90005-1 
37. Bagby RM, Taylor GJ, Parker JD. The Twenty-item Toronto Alexithymia Scale-II. Convergent, discriminant, and concurrent validity. J Psychosomat Res. 1994;38(1):33-40. doi:10.1016/00223999(94)90006-X

38. Parker JDA, Taylor GJ, Bagby M. Alexithymia and the processing of emotional stimuli: an experimental study. New Trends in Exp Clin Psychiat. 1993;9:9-14.

39. Wen L, Shi-San QI, Preliminary A. Revision of Luthans Psychological Capital Questionnaire. Chinese J Clin Psychol. 2009;17(2):25-27. doi:10.16128/j.cnki.1005-3611.2009. 02.020

40. Steiger JH. Structural model evaluation and modification: an interval estimation approach. Multivariate Behav Res. 1990;25(2):173-180. doi: $10.1207 / \mathrm{s} 15327906 \mathrm{mbr} 2502 \_4$

41. Schreiber JB, Nora A, Stage FK, et al. Reporting structural equation modeling and confirmatory factor analysis results: a review. $J$ EducRes. 2006;99(6):323-337. doi:10.2307/27548147

42. Wang Y, Xiao H, Zhang X, et al. The role of active coping in the relationship between learning burnout and sleep quality among college students in China. Front Psychol. 2020;11:647. doi:10.3389/ fpsyg.2020.00647

43. Bryant AN. Ecumenical worldview development by gender, race, and worldview: a multiple-group analysis of model invariance. Res High Educ. 2011;52(5):460-479. doi:10.1007/s11162-0109206-z

44. Terock J, Van der Auwera S, Janowitz D, et al. Childhood trauma and adult declarative memory performance in the general population: the mediating effect of alexithymia. Child Abuse Negl. 2020;101:104311. doi:10.1016/j.chiabu.2019.104311

45. Chen L, Xu L, You W, et al. Prevalence and associated factors of alexithymia among adult prisoners in China: a cross-sectional study. Bmc Psychiatry. 2017;17(1):287. 287. doi:10.1186/s12888017-1443-7

46. Franzoni E, Gualandi S, Caretti V, et al. The relationship between alexithymia, shame, trauma, and body image disorders: investigation over a large clinical sample. Neuropsychiatr Dis Treat. 2013;9:185-193. doi:10.2147/ndt.534622

47. Berenbaum H. Childhood abuse, alexithymia and personality disorder. J Psychosomat Res. 1996;41(6):585-595. doi:10.1016/ S0022-3999(96)00225-5

48. Glaser D. Emotional abuse and neglect (psychological maltreatment): a conceptual framework. Child Abuse Negl. 2002;26(6):697-714. doi:10.1016/S0145-2134(02)00342-3
49. Kooiman CG, Vellinga SV, Spinhoven P, et al. Childhood adversities as risk factors for alexithymia and other aspects of affect dysregulation in adulthood. Article. Psychother Psychosom. 2004;73 (2):107-116. doi:10.1159/000075542

50. van der Kolk BA, Perry JC, Herman JL. Childhood origins of self-destructive behavior. Am J Psychiatry. 1991;148 (12):1665-1671. doi:10.1176/ajp.148.12.1665

51. Paivio SC, McCulloch CR. Alexithymia as a mediator between childhood trauma and self-injurious behaviors. Child Abuse Negl. 2004;28 (3):339-354. doi:10.1016/j.chiabu.2003.11.018

52. Mulvihill D. The health impact of childhood trauma: an interdisciplinary review, 1997-2003. Issues Compr Pediatr Nurs. 2005;28 (2):115-136. doi:10.1080/01460860590950890

53. Nogovitsyn N, Addington J, Souza R, et al. Childhood trauma and amygdala nuclei volumes in youth at risk for mental illness. Psychol Med. 2020:1-8. doi:10.1017/s0033291720003177.

54. Selvaraj PR, Bhat CS. Predicting the mental health of college students with psychological capital. J Ment Health. 2018;27 (3):279-287. doi:10.1080/09638237.2018.1469738

55. Broekhof R, Rius-Ottenheim N, Spinhoven P, et al. Long-lasting effects of affective disorders and childhood trauma on dispositional optimism. $J$ Affect Disord. 2015;175:351-358. doi:10.1016/j. jad.2015.01.022

56. Simmenjanevska K Motivation in psychotraumatology: the relationship between childhood trauma and self-efficacy, self-control and conscientiousness in old age. $\mathrm{PhD}$ thesis. University of Zurich; 2014. doi: 10.5167/uzh-101642

57. Li J, Huang L. The psychological capital accumulation of middle school students in Quake-Stricken Wenchuan. Asian Soc Sci. 2014;10 (21):128-134. doi:10.5539/ass.v10n21p128

58. Cole K, Daly A, Mak A. Good for the soul: the relationship between work, wellbeing and psychological capital. J Socio-Econ. 2009;38 (3):464-474. doi:10.1016/j.socec.2008.10.004

59. Laschinger HKS, Nosko A. Exposure to workplace bullying and post-traumatic stress disorder symptomology: the role of protective psychological resources. J Nurs Manag. 2015;23(2):252-262. doi: 10.1111 jonm. 12122

60. Hobfoll SE. The influence of culture, community, and the nested-self in the stress process: advancing conservation of Resources Theory. Appl Psychol. 2001;50(3):337-421. doi:10.1111/1464-0597.00062

61. China: China Statistical Yearbook. Available from: http://www.stats. gov.cn/tjsj/ndsj/2019/indexch.htm. Accessed. 2019.
Psychology Research and Behavior Management

\section{Publish your work in this journal}

Psychology Research and Behavior Management is an international, peer-reviewed, open access journal focusing on the science of psychology and its application in behavior management to develop improved outcomes in the clinical, educational, sports and business arenas. Specific topics covered in the journal include: Neuroscience, memory and decision making; Behavior modification and management; Clinical applications; Business and sports performance management; Social and developmental studies; Animal studies. The manuscript management system is completely online and includes a very quick and fair peer-review system, which is all easy to use. Visit http://www. dovepress.com/testimonials.php to read real quotes from published authors. 